the $F^{\prime}$-III (chloroform) fraction there wore less gibberellinlike substances in girdled than ungirdled at $R_{F} 0-0.5$. In both the $F-I V$ (acid) and $F-V$ (acid butanol) fractions there was a greatly increased gibberellin activity in the ringed fruit. In the $F-I V$ there were poaks from $R_{F}$ 's $0 \cdot 2-0 \cdot 7$, and $R_{F} 0 \cdot 9-1 \cdot 0$. In the $F-\mathrm{V}$ fraction there were three peaks, $R_{F}$ 's $0 \cdot 1-0 \cdot 3,0 \cdot 5-0 \cdot 6$, and $0.9-1 \cdot 0$.

These results show that ringing is associated with great differences in content of gibberollin-like substances in 'Black Corinth' berries, and the increase in certain gibberellins may cause the enlarged fruit. Previous work with crude extracts failed to reveal an increase in hormone content in auxin and gibberellin as a result of ringing ${ }^{5}$. It is now necessary to discover which of the known gibberellins are involved in fruit enlargement, and hopefully the mechanisms involved. These results also indicate that many types of gibberellins are present in grapes, and that they occur in extremely high amounts.

This investigation was supported by National Science Foundation grant $G B-1055$.

ROBert J. Whaver Robert M. POOI

Department of Viticulture and Enology, University of California, Davis.

${ }^{1}$ Jacob, H. E., Proc. Amer. Soc. Hort. Sci, 25, 223 (1928). 2 Weaver, R. J., and McCune, S. B., Nature, 181, 851 (1958), 2 Kobler, D., and Lang, A., Plant Physiol, 38, 555 (1963).

4 Lockhart, J. A., Proc. U.S. Nat. Acald. Sci., 42, 841 (1950).

'Coombe, B. G., P'lant Physiol., 35, 241 (1960).

\section{Timber Decay caused by Bacteria}

Is an inspoction of a ninety-year-old building in Copenhagen some of the foundation piles were found to be soft from the surface inwards to a depth of 20-30 mm.

Samples of the softened wood of Pinus silvestris and Picea abies from 16 piles and one whole pile wore taken for microseopic examination.

On cross-soction of the wood, stained with safranin and aniline blue in picric acid, a number of the tracheids appeared to be heavily stained, especially along tho rays and then in a moro scattered pattern among apparently hoalthy cells. The stained parts consist of more or less fibrous, granular or amorphous masses togethor with different micro-organisms. In longitudinal radial sections the decay pattern is more clearly visible. First, small

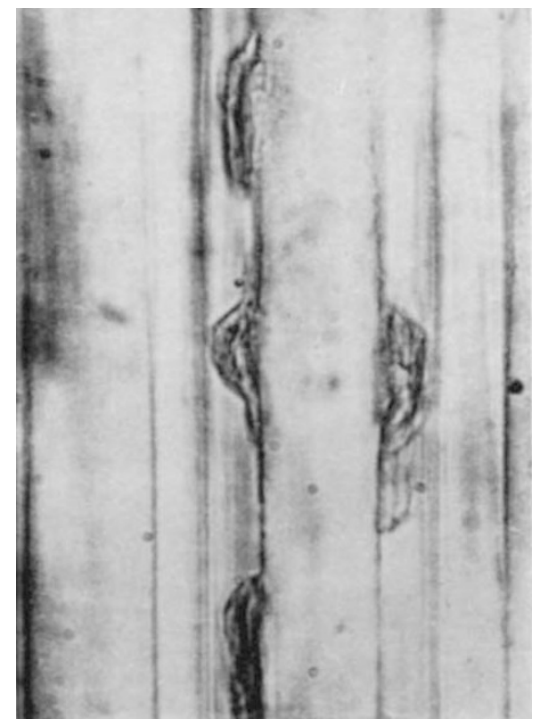

Fig. 1. Decay in tracheidal walls of Pinus silvestris $(x c, 930)$ conical depressions are seen to extend from the cell lumen into the secondary wall; the dopressions spread more or less irregularly to all sides in the secondary wall but do not ponetrate the middle lamella. The tracheids adjacent to the rays are attacked first; next, tracheids at the growth ring boundary; then the attacks are more scattered. The passage of the micro-organisms seoms to be through the ray cells and the borderod pits in the tracheids.

From the decay pattern it was concluded that the microorganisms in question might be cellulose-decomposing. Some species of bacteria were observed together with fine hyphae and spores of an actinomycete.

In seloctive isolation experiments some aerobe sporulating bacteria and an actinomycoto were isolated. The nutrient used was a cellulose-mineral salt medium with 0.01 por cent yeast extract. After inoculation, the enrichment culture was heated for $1 \mathrm{~h}$ at $60^{\circ} \mathrm{C}$.

The isolates woro proved to be cellulose-decomposing, but it has not yet been possible to develop in cultures the decay in wood cell walls doscribed above. The actinomycete has beon referred to the genus Micromonospora.

$$
\text { L. HARMSEN }
$$

Mycological Laboratory,

Teuhnological Institute,

2 Hagemannsgade, Copenhagen.

T. VINCENTS NISSEN

Technical University of Copenhagen,

83 Sølvgade, Copenhagen.

\section{Response of Oxidation and Phosphorylation in Citrus Mitochondria to Arsenate}

Commercial application of lead arsenate to citrus foliage has long been used to accelerate reduction of acidity in grapefruit. The effectivo moiety has been found to be arsenate. Control of citric acid accumulation by some other means would be highly desirable and is the object of the work recorded here.

Arsenate competition with phosphate as an electron acceptor indicates that phosphorylation could be the key to the mechanism of citric acid accumulation. Citrus mitochondrial preparations capable of oxidative phosphorylation offor good material for phosphate esterification investigations ${ }^{1}$. This communication will also amplify the previous brief account of mitochondrial isolation ${ }^{2}$.

Cell particulate fractions were isolated from orange fruit at different stages of maturity according to the following procedure. The orange fruit sections of Citrus sinensis (L.) Osbeck (generally about $100 \mathrm{~g}$ fresh weight) were separated from the peel immediately after gathering and cooled to $0^{\circ} \mathrm{C}$. All solutions, equipment, and sub. sequent operations were carried out at $0^{\circ}-2^{\circ} \mathrm{C}$, except the measured reactions which were at $25^{\circ} \mathrm{C}$. The homogenizing solution consisted of sucrose $0.25 \mathrm{M}$, mannitol $0.37 \mathrm{M}$, ethylenediamino tetraacetic acid (EDTA) $0.005 \mathrm{M}$, and cysteine $0.004 \mathrm{M}$ adjusted to $p \mathrm{H} 7.0$ according to Wiskich et al. ${ }^{3}$. The mitochondrial suspending solution contained mannitol $0.3 \mathrm{M}$, tris $0.01 \mathrm{M}$, magnesium chloride $0.005 \mathrm{M}$, and was adjusted to $p \mathrm{H} 7 \cdot 0$ with potassium hydroxide.

The juice vesicles werc ruptured under the homogeniz. ing solution, $1: 1(\mathrm{w} / \mathrm{v})$, by hand with the aid of a stainless stecl grater. Because of the generally high acidity of the juice (up to $50 \mathrm{~m}$.equiv. $/ 100 \mathrm{~g}$ fresh weight), the $p H$ was maintained at 7.0 by continuous addition of potassium hydroxide, using the bromthymol blue indicator.

The homogenate was then strained through four layers of cheese-cloth and the filtrate centrifuged at $500 \mathrm{~g}$ for 5 min and the debris discarded. The supernatant solution was then centrifuged at $15,000 \mathrm{~g}$ for $15 \mathrm{~min}$ and the pellet suspended with the aid of a Potter-type homogenizer in $1.00 \mathrm{ml}$. of suspending solution per $100 \mathrm{~g}$ original fresh weight. A slow speed ( $500 \mathrm{~g}$ for $5 \mathrm{~min}$ ) was used to further remove non-mitochondrial nitrogen ${ }^{4}$. Unless otherwiso 